\title{
Is Nd-Yag laser treatment for upper gastrointestinal bleeds of benefit in a district general hospital?
}

\author{
A.C. Homer, S. Powell and F.R. Vicary \\ Department of Gastroenterology, Whittington Hospital, London N19 5NF, UK.
}

\begin{abstract}
Summary: 104 consecutive patients with upper gastrointestinal bleeding admitted to a district general hospital over a period of 20 months were considered for laser photocoagulation. 58 patients were found to have peptic ulcers, of which $\mathbf{4 2}$ had stigmata of recent haemorrhage accessible to laser photocoagulation. 17 were treated with a Nd-YAG laser and 25 were managed conservatively. There was no significant difference in the number of patients who re-bled and required surgery, mortality rate, length of stay in hospital or the amount of blood transfusion required in either group. We suggest that the routine use of a laser for bleeding peptic ulcers in a district general hospital is not justified.
\end{abstract}

\section{Introduction}

Patients who rebleed after admission to hospital with upper gastrointestinal haemorrhage have a high mortality rate (Jones, 1956). The single most useful factor for predicting rebleeding is stigmata of recent haemorrhage (SRH) seen at endoscopy (Foster et al., 1978). Various endoscopic techniques have been tried in an attempt to modify the course of rebleeding. The Nd-YAG laser has been shown experimentally to be safe and effective in vessel coagulation (Bown et al., 1980). We set out to see if there is a place for laser treatment of bleeding peptic ulcers in a district general hospital. This report is of a prospective randomized controlled trial of Nd-YAG laser treatment in 42 unselected patients presenting to this hospital over a period of 20 months.

\section{Methods}

One hundred and four patients were admitted to the Whittington Hospital between November 1981 and July 1983 with suspected upper gastrointestinal bleeds. All such cases come under the care of this department. All patients gave written informed consent before inclusion in the trial. The protocol was approved by the District Ethical Committee.

\footnotetext{
A.C. Homer, M.R.C.P.; S. Powell, M.A., M.B. and F.R. Vicary, F.R.C.P.

Correspondence: A.C. Homer.

Accepted: 8 May 1984
}

\section{Trial design}

Patients were included in the trial if they fulfilled the criteria of having a single duodenal or gastric ulcer showing SRH, considered to be the source of bleeding, and accessible to the laser beam. SRH were defined as: 1. a visible vessel whether actively bleeding or not; 2 . a diffuse area of oozing at the base of an ulcer but no single visible vessel; 3 . a small clot in an ulcer crate which could not be washed away.

The protocol allowed fresh clot to be washed away, but no attempt was made to dislodge firm clot. If all the criteria were fulfilled the patient was allocated by random card selection to receive either laser or placebo treatment. Following endoscopy all patients were given cimetidine $1 \mathrm{~g}$ daily by mouth and returned to the care of the admitting clinician. All further decisions on management were made by him on conventional clinical grounds. He was unaware as to whether the patient had had laser treatment.

\section{Assessment of outcome}

Patients either recovered, rebled and had emergency surgery, or died. Criteria for rebleeding were: 1 . A fall in blood pressure or central venous pressure (CVP) readings with a concomitant rise in pulse rate; 2 . Further haematemesis; 3 . Continued passage of fresh melaena.

In this hospital it is policy for rebleeds to go to surgery. Surgery confirmed all rebleeds suspected on clinical grounds except 2 . In these two cases surgery was not indicated despite continued rebleeding. En- 
doscopy was not repeated to confirm rebleeding before surgery.

\section{Endoscopic and laser procedure}

All patients were sedated with intravenous diazepam as Diazemuls. Gastric lavage was not performed. Endoscopy was carried out using an Olympus G.I.F.$Q$ fibrescope. A neodymium ytrium aluminium garnet (Nd-YAG) laser was used (MBB Medilas). The laser beam was transmitted via a flexible fibre which passed down the biopsy channel of the endoscope. Coaxial flow of carbon dioxide at 1 litre/min cooled the tip of the fibre and cleared blood away from an actively bleeding lesion. A nasogastric tube was passed at the start of the procedure and connected to an underwater sealed drain. Bubbling indicated an adequate escape route for any excess carbon dioxide in the stomach.

Power was set at 60-70 watts before insertion of the fibre, and delivered in electronically limited pulses of $0.5 \mathrm{sec}$. The laser tip was held approximately $5 \mathrm{~mm}$ from the lesion and fired until the target area was charred indicating photocoagulation (usually 7-8 pulses, maximum 17). All photocoagulation was either performed or directly supervised by one of us (FRV).

\section{Results}

One hundred and four consecutive patients with suspected upper gastrointestinal bleeds were endoscoped, usually the next morning (mean time of endoscopy after admission $=23 \mathrm{~h}$ ). The time of endoscopy after first clinical evidence of bleeding varied from 3 to $161 \mathrm{~h}$ depending on the interval between onset of bleeding and presentation to hospital (mean time $48 \mathrm{~h}$ ). The causes of bleeding are shown in Table I. Sixteen patients with peptic ulcers, 8 each with gastric and duodenal ulcers were excluded from the

Table I Causes of bleeding at endoscopy in 104 patients with upper gastrointestinal haemorrhage

\begin{tabular}{lc}
\hline & No. of patients \\
\hline Duodenal ulcer & 30 \\
Gastric ulcer & 28 \\
Mallory-Weiss tear & 9 \\
Varices & 9 \\
Gastritis and gastric & 8 \\
$\quad$ erosions & 3 \\
Oesophagitis and ulcers & 2 \\
Duodenitis & 1 \\
Vascular anomaly & 3 \\
Carcinoma stomach & 11 \\
No abnormality found & \\
\hline
\end{tabular}

trial and the reasons for this are shown in Table II. Of the 42 patients entered into the trial 17 were allocated to receive laser treatment and 25 were allocated as controls.

Table III shows a comparison of the 2 groups whilst the results are shown in Table IV. There was no significant difference between the laser treated group or controls in the number of rebleeds, mortality, length of stay in hospital or the amount of blood transfusion required. Most of the patients who rebled (10 out of a total of 11 in both groups) had actively bleeding lesions at the end of endoscopy whether treated with the laser or not. Only one patient who had a visible vessel which was not actively bleeding at the end of the procedure went on to rebleed.

Two of the 8 patients in the control group who rebled subsequently died. Surgery was not thought to be appropriate for either patient. One was an 82 year old woman with a gastric ulcer and severe cardiovascular disease. The other was a 77 year old man with a duodenal ulcer, alcoholic cirrhosis and liver failure.

\section{Discussion}

The place of laser photocoagulation in upper gastrointestinal bleeding has not been defined. There have been 5 controlled trials published $(3 \mathrm{Ng}$-YAG and 2 argon) since Keifhaber published his results in 1978 (Keifhaber et al., 1978). Three have shown the sameresults as ours - no significant reduction in mortality or rebleeding following treatment (Ihre et al., 1981; Rutgeerts et al., 1982; Vallon et al., 1981). A significant reduction in mortality using an argon laser has been reported (Swain et al., 1981), but further statistical analysis of the results does not support this (Henry \& Langman, 1982). Macleod et al. (1983) showed a significant reduction in rebleeding requiring surgery using a Nd-YAG laser, but carefully selected their 20 patients for the trial from 698 acute non-

Table II Reason for exclusion from trial in 16 cases of peptic ulcer

\begin{tabular}{ll}
\hline & No. of patients \\
\hline $\begin{array}{l}\text { No SRH seen after careful washing } \\
\text { of ulcer }\end{array}$ & 5 \\
$\begin{array}{l}\text { Source of bleeding identified but } \\
\text { inaccessible }\end{array}$ & 3 \\
$\begin{array}{l}\text { Source not identified due to } \\
\text { bleeding or firm clot } \\
\begin{array}{l}\text { Major sources identified in more } \\
\text { than 1 ulcer }\end{array}\end{array}$ & 4 \\
\hline
\end{tabular}


Table III Comparison of laser-treated and control groups

\begin{tabular}{lcc}
\hline & $\begin{array}{c}\text { Laser-treated } \\
(\mathrm{n}=17)\end{array}$ & $\begin{array}{c}\text { Control } \\
(\mathrm{n}=25)\end{array}$ \\
\hline Duodenal ulcer & 9 & 13 \\
Gastric ulcer & 8 & 12 \\
Mean age & 58 & 65 \\
Sex distribution: male/female & $12 / 5$ & $19 / 6$ \\
Mean initial haemoglobin concentration (g/dl) & 9.2 & 10.1 \\
Number of patients with an initial systolic blood pressure less than $100 \mathrm{~mm} \mathrm{Hg}$ & 4 & 4 \\
\hline
\end{tabular}

Table IV Comparison of results in laser-treated and control groups

\begin{tabular}{lccc}
\hline & Laser-treated & Control & Statistics \\
\hline Duodenal ulcer rebleeds & 3 & 4 & $P=0.9^{*}(\mathrm{NS})$ \\
Gastric ulcer rebleeds & 0 & 4 & $P=0.2+(\mathrm{NS})$ \\
Total rebleeds & 3 & 8 & $P=0.5^{*}(\mathrm{NS})$ \\
Deaths & 0 & 2 & $P=0.7+(\mathrm{NS})$ \\
Units blood transfused (mean) & 5.18 & 4.74 & $P>0.5 \pm(\mathrm{NS})$ \\
Days in hospital (mean) & 8.3 & 10.8 & $P=0.3 \ddagger(\mathrm{NS})$ \\
\hline
\end{tabular}

\footnotetext{
* Chi-square test with Yates' correction

$\dagger$ Fisher's exact test two-tailed

¥2 Sample t-test

NS $=$ not significant
}

variceal upper gastrointestinal bleeds. Only 8 patients actually received laser treatment.

The effectiveness of any new treatment has to be evaluated by many trials over a period of time. It is important also to assess any hazards involved and the cost. A rough estimate of the cost per person of this high technology medicine for the number of patients we have seen over the last 20 months is $£ 340$.

The technique is difficult and not without hazards. Our trial was stopped following almost fatal exsanguination of a patient immediately after laser treatment. Attempted coagulation of an oozing artery in the base of duodenal ulcer caused massive arterial bleeding, a complication previously described (Rutgeerts et al., 1982). Fortunately our patient survived.

The present trial was terminated early and the significance of the findings regarding rebleeding rate in the treatment and control groups must be interpreted, in part, with reference to the sample sizes, which are low. An estimate of the power of the statistical test used to test the difference in overall rebleeding rate can be made, assuming that the observed difference in proportions refiects a true difference, rather than a sampling variation where there is, in fact, no underlying difference. This shows a power of approximately $20 \%$ (2-tail); i.e. such a trial has a chance of approximately 1 in 5 of detecting, at a significance level of $5 \%$, a true difference in proportions of $0.18(3 / 17)$ and $0.32(8 / 25)$. The sample size required to substantiate such a difference with a power of $90 \%$ is approximately 230 .

We have attempted to assess whether Nd-YAG laser photocoagulation has any significant impact on the clinical outcome of patients admitted with bleeding from peptic ulcers. Although our numbers are small, they represent an unselected sample of patients presenting to a district general hospital over a period of 20 months. There was no significant improvement in outcome with this treatment. This supports previous findings. We believe that improvement in mortality rates for upper gastrointestinal bleeding can best be brought about at present by prompt or even prophylactic surgery for those known to be at high risk for rebleeding (SRH at endoscopy).

We suggest that there can be no justification for the cost, time and potential hazards involved in providing laser photocoagulation for bleeding peptic ulcers in a UK district general hospital. 


\section{Acknowledgements}

The authors wish to acknowledge M.B.B. \& Co. of West Germany for the use of their laser machine. Also to Miss L. Sims for typing the manuscript.

\section{References}

BOWN, S.G., SALMON, P.R., STOREY, D.W., CALDER, B.M., KELLY, D.F., ADAMS., PEARSON, N. \& WEAVER, B.M.O. (1980). Nd-YAG laser photocoagulation in the dog stomach. Gut, $21,818$.

FOSTER, D.N., MILOSZEWSKI, K.J.A. \& LOSOWSKY, M.S. (1978) Stigmata of recent haemorrhage in diagnosis and prognosis of upper gastrointestinal bleeding. British Medical Journal, 1, 1173.

HENRY, D.A. \& LANGMAN, M.J.S. (1982). Argon laser photocoagulation in bleeding peptic ulcers. Lancet, i, 99.

IHRE, T., JOHANNSON, C., SELIGSON, U. \& TORNGREN, S. (1981). Endoscopic YAG laser treatment in massive upper gastrointestinal bleeding. Scandinavian Journal of Gastroenterology, 16, 633.

JONES, F.A. (1956). Haematemesis and malaena. Gastroenterology, 30 (2), 166.
KEIFHABER, P., MORITZ, K., SCHILDBERG, F.W. \& FEIFEL, G. (1978). Endoskopische Nd-YAG laser coagulation blutender akuter und chronischer ulcera. Langenbecks Archir fur Chirurgie, 347, 567.

MACLEOD, I.A., MILLS, P.R., MACKENZIE, J.F., JOFFE, S.N., RUSSELL, R.I. \& CARTER, D.C. (1983). Neodymium yttrium aluminium garnet laser photocoagulation for major haemorrhage from peptic ulcers and single vessels: a single blind controlled study. British Medical Journal, 286, 345.

RUTGEERTS, P., VANTRAPPEN, G., BROECKAERT, L., JAN SEENS, J., COREMANS, G., GEBOES, K. \& SCHURMANS, P. (1982). Controlled trial of YAG laser treatment of upper digestive haemorrhage. Gastroenterology, 83, 410.

SWAIN, C.P., BOWN, S.G., STOREY, D.W., KIRKHAM, J.S., NORTHFIELD, T.C. \& SALMON, P.R. (1981). Controlled trial of argon laser photocoagulation in bleeding ulcers. Lancet, ii, 1313.

VALLON, A.G., COTTON, P.B., LAURENCE, B.H., ARMENGOLMIRO, J.R. \& SALORD OSES, J.C. (1981). Randomised trial of endoscopic argon laser photocoagulation in bleeding peptic ulcers. Gut, 22, 228. 